\title{
Perceptions of effective relationships in an institutional care setting for older people
}

\begin{tabular}{|c|c|}
\hline \multicolumn{2}{|l|}{$\begin{array}{l}\text { Authors: } \\
\text { Vera Roos }{ }^{1}\end{array}$} \\
\hline \multicolumn{2}{|c|}{$\begin{array}{l}\text { Affiliations: } \\
{ }^{1} \text { Africa Unit for } \\
\text { Transdisciplinary Health } \\
\text { Research, North-West } \\
\text { University, Potchefstroom } \\
\text { Campus, South Africa }\end{array}$} \\
\hline \multicolumn{2}{|c|}{$\begin{array}{l}\text { Correspondence to: } \\
\text { Vera Roos }\end{array}$} \\
\hline \multicolumn{2}{|c|}{$\begin{array}{l}\text { Email: } \\
\text { vera.roos@nwu.ac.za }\end{array}$} \\
\hline \multicolumn{2}{|c|}{$\begin{array}{l}\text { Postal address: } \\
\text { Private Bag X6001, Internal } \\
\text { Box 206, North-West } \\
\text { University, Potchefstroom } \\
\text { 2520, South Africa }\end{array}$} \\
\hline \multicolumn{2}{|c|}{$\begin{array}{l}\text { Dates: } \\
\text { Received: } 30 \text { Apr. } 2013 \\
\text { Accepted: } 02 \text { May } 2014 \\
\text { Published: } 24 \text { Oct. } 2014\end{array}$} \\
\hline \multicolumn{2}{|c|}{$\begin{array}{l}\text { How to cite this article: } \\
\text { Roos, V., \& Du Toit, F. } \\
\text { (2014). Perceptions of } \\
\text { effective relationships in } \\
\text { an institutional care setting } \\
\text { for older people. SA Journal } \\
\text { of Industrial Psychology/ } \\
\text { SA Tydskrif vir } \\
\text { Bedryfsielkunde, 40(1), Art. } \\
\text { \#1139, } 9 \text { pages. http:// } \\
\text { dx.doi.org/10.4102/sajip. } \\
\text { v40i1.1139 }\end{array}$} \\
\hline \multicolumn{2}{|c|}{$\begin{array}{l}\text { Copyright: } \\
\text { (C) 2014. The Authors. } \\
\text { Licensee: AOSIS } \\
\text { OpenJournals. This work } \\
\text { is licensed under the } \\
\text { Creative Commons } \\
\text { Attribution License. }\end{array}$} \\
\hline \multicolumn{2}{|c|}{ Read online: } \\
\hline 回的回 & $\begin{array}{l}\text { Scan this QR } \\
\text { code with your } \\
\text { smart phone or } \\
\text { mobile device } \\
\text { to read online. }\end{array}$ \\
\hline
\end{tabular}

Orientation: The relocation of older people to residential facilities has implications for their relationships.

Research purpose: This article reports older residents' perceptions of effective relationships.

Motivation for the study: Effective relationships protect against loneliness and depression and contribute to well-being. The facility was identified by a social worker as a showcase for effective relationships, but it was not clear what these consist of.

Research approach, design and method: The World Café, a qualitative, participatory action research method, was applied to an economically deprived, urban facility caring for older people in Gauteng, South Africa. Three positively framed questions elicited perceptions from participants (nine men, ten women, aged 65-89). Visual and textual data were obtained and thematically analysed until saturation had been achieved. Themes were then subjected to deductive direct content analysis in terms of Self-Interactional Group Theory (SIGT).

Main findings: Older residents perceive care managers as friendly and trustworthy and co-residents as caring. Care managers were seen as flexible, empathetic and congruent leaders and they confirmed residents. Relationships between residents were parallel-defined with relational qualities such as empathy and unconditional acceptance. Residents' needs for privacy were honoured and they felt confirmed. Group dynamics were underpinned by caring and a stimulating environment provided opportunities for engagement.

Practical/managerial implications: Relationships between managers and consumers are facilitated by flexibility, empathy, congruence and unconditional acceptance. Supportive group dynamics develop when people confirm and accept one another. A stimulating environment that encourages continuous and close interpersonal contact contributes to effective relationships.

Contribution/value-add: Effective relationships should be understood on different levels.

\section{Introduction}

Effective relationships are reciprocal caring, warm, satisfying and trusting and enable people to maintain relative comfort, security and freedom from anxiety (Brownie \& Hortsmanshof, 2012; Ryff \& Singer, 1998; Smith-Acuña, 2011; Vorster, Roos \& Beukes, 2013). People in satisfying relationships are able to express and address their own needs as well as those of the relationship (Smith-Acuña, 2011). Research indicates that effective relationships can combat emotional and social loneliness, which contribute to depression in old age (Brownie \& Hortsmanshof, 2012; Taube, Kristensson, Midlov, Holst \& Jakobsson, 2013).

In contrast, people with less successful relationships reported feeling distanced, discontented, blamed and disconnected (Smith-Acuña, 2011; Vorster et al., 2013). According to Fromm (1985), the experience of disconnectedness is a source of intense anxiety, which Vorster et al. (2013) found to contribute to psychological discomfort. Although this study focused on the relational perceptions of older people in an institutional residential setting, it is also relevant to organisations in which members are continuously interacting with one another and with those in leadership positions. Effective relationships have been found to be directly related to older people's quality of life (Brownie \& Horstmanshof, 2012; Van Biljon \& Roos, 2012). Effective relationships are therefore important for mental health, particularly in an institutional setting, because people spend a large part of their lives in an organised setting, albeit in different positions and in different roles (Kitching, Roos \& Ferreira, 2012; SmithAcuña, 2011). It is thus helpful to determine what people regard as effective relationships in an institutional setting. 


\section{Research purpose and objectives}

Theorists and practitioners recognise the importance of relationships in promoting mental health, wellness or wellbeing in an institutional setting, but little is known about relationships that are perceived as effective. Based on the preceding presentation of the problem, this study therefore set out to explore what older people perceived as effective relationships in an institutional residential setting.

\section{Literature review}

The purpose of this research was to elicit the perceptions of older people about effective relationships in an institutional residential setting by means of positively framed questions. Research into relationships in settings for older people generally focuses on what is not working or what is problematic (Anthony, Suchman, \& Penelope, 2011; Grenade $\&$ Boldy, 2008). Studies have found that older people in organised care institutions typically experience depression and loneliness (Grenade \& Boldy, 2008; Roos \& Malan, 2012; Shabangu \& Roos, 2012; Taube et al., 2013; Victor, Scambler \& Bond, 2009). Older people tend to reminisce about relationships that have ended as a result of different kinds of losses: relational losses, the loss of activities they had engaged in previously or environmental changes (Lalive d'Epinay, Cavalli \& Spini, 2003; Roos \& De Jager, 2010; Roos \& Klopper, 2010; Roos \& Malan, 2012). Research conducted in South Africa confirms that relationships in institutional settings for older people can contribute to unhealthy group dynamics, isolation and rejection (Roos \& Malan, 2012; Roos \& Nel, 2010; Shabangu \& Roos, 2012).

For the purposes of this study, relationships are regarded as the continuous, reciprocal verbal and non-verbal interactions between people (Hargie, 2011; Smith-Acuña, 2011; Suchman, 2006; Watzlawick, Bavelas \& Jackson, 2011). These interactions consist of subjective experiences (impact) on an intrapersonal level and reactions on an interindividual level. The interactions take place in a particular interpersonal context, embedded in broader environments (Roos, in press; Vorster et al., 2013). The inter-individual level of the interaction consists of relational qualities that may be described as effective or ineffective based on the subjective evaluation of the impact as well as the degree to which participants are able to address their needs in the relationships (Chigeza, De Wet, Roos \& Vorster, 2013; Chigeza \& Roos, 2011; Vorster et al., 2013; Roos \& Malan, 2012; Roos, in press). Ineffective relational qualities are observed when people report psychological discomfort, which is related to their interactional style, and the impact thereof on other people, which results in their needs not being met (Vorster et al., 2013). An interactional style is the patterned nature of a person's interactions with other people, which may or may not be context-specific (Vorster, 2011).

Research on relationships in an institutional residential setting was conducted in relation to co-residents and care managers. In relation to co-residents, relationships are promoted by proximity, regular contact and a variety of interactions within the institution as well as externally (Brownie \& Horstmanshof, 2012; Roos \& Malan, 2012; Roos \& Nel, 2010; Van Biljon \& Roos, 2012). Furthermore, older persons who had regular contact with others and the opportunity to engage in a variety of interactions experience subjectively less loneliness (Roos \& Malan, 2012; Taube et al., 2013). In relation to care managers, residents emphasised their flexibility as well as their care and helpfulness (Murphy, O'Shea \& Cooney, 2007). The ethos of care within a residential facility may be one of the most significant factors to have an impact on a resident's quality of life (Murphy et al., 2007).

Following the systems theory, and specifically the patterned nature of systems, information about what is occurring on one part of the system can give an indication of what is happening on the other part of the system (Smith-Acuna, 2011). Consequently, by gaining an understanding of effective relationships from the perspective of the recipients of the interaction it is possible to make deductions about the care managers' or co-residents' interactional style. The reciprocal and continuous nature of interactions makes it impossible to focus on all their components at the same time (Smith-Acuña, 2011; Vorster et al., 2013). In the present study, effective relationships were therefore studied from the perspective of the residents.

\section{Theoretical framework}

Self-Interactional Group Theory (SIGT) is proposed as a means of explaining the interactions between people within a particular context and on three levels: the intra-individual level, the inter-individual level and the group level (Roos, in press). The intra-individual level indicates the status of the inter-individual and group level: what occurs at the intra-individual level (emotions and perceptions) provides the first indicator of what is taking place between people (Hogan, 2011; Lazarus, 2006). On the inter-individual level the relational qualities suggested by Vorster et al. (2013) are grouped according to inter-individual level indicators, which are derived from interpersonal and communication theories, namely: (1) Context in which interactions takes place; (2) definition of the relationship as complementary or parallel-defined relationships, or a symmetrically-defined relationship if the definition is challenged by the participants in the relationship; (3) relational qualities of those who are interacting, such as clarity of expression and presentation of the self, psychological closeness or distance, empathy, unconditional acceptance, congruency, rigidity or flexibility, ability to communicate on a higher logical level, problemsolving skills and locus of control; (4) motivation for the interaction between people in terms of needs fulfilment and how effectively they express their needs. Basic human needs include a need for confirmation (Hycner \& Jacobs, 1995) and recognition, physical and emotional care, safety, affiliation, actualisation and opportunities for spiritual experiences (Fiske, 2000); (5) the interactional nature of the relationship between people refers to continuous and circular processes 
of acting and reacting. In accordance with SIGT, the group level refers to intra- and inter-group level dynamics. The interactions between people are always embedded in broader environments (Roos, in press).

In the next section, the research method will be discussed, followed by the findings and a discussion of the findings, linked to relevant literature. Recommendations and limitations will be followed by a conclusion.

\section{Research design \\ Research approach}

A qualitative research method was followed to investigate the perceptions of effective relationships of the residents in a residential facility (Braun \& Clarke, 2013). According to Neuman (2000), qualitative research can obtain rich data, is sensitive to context and can describe human experiences, perceptions, motivations and behaviour (Clissett, 2008). Since not much is known about effective relationships in residential care facilities, an inductive and exploratory approach was followed (Creswell, 2007).

\section{Research strategy}

Participatory action research was used because participants participated in creating knowledge in action (Reason \& Bradbury, 2006). Drawing on this method of research, and by using positively framed questions, researchers and participants collaborate to discover the strengths, passions and life-giving powers in relationships together (Reason \& Bradbury, 2006).

\section{Research method \\ Research setting}

The research took place in an urban setting caring for people older than 60 years in Gauteng, South Africa. The facility is managed by a small team, consisting of the manager, a secretary and eight volunteers. They will be referred to as 'care managers' throughout the study. This setting is regarded as economically deprived since 40 of the residents are subsidised by the South African Women's Federation (SAWF) and the rest depend on their state pension (R1270 per month or, in the case of people older than 75 years, R1270 + R20). The particular setting was selected to exemplify the importance of effective relationships because a social worker, who was, amongst other duties, also responsible for the psychosocial well-being of the organisation, regarded it as a model for effective relationships and requested an assessment of the relational perceptions of its residents.

\section{Entree and establishing researcher roles}

A social worker approached the researchers at a workshop on the description of loneliness as a relational phenomenon and asked them to study the perceptions of relationships in a particular residential setting for older people. On the day of data gathering, the social worker explained the aim of the research to the residents and introduced the researchers.
The researchers asked the participants if they wanted to participate in the study and explained what would be expected of them.

\section{Sampling}

The population in the care setting consisted of 72 white older people (38 men and 34 women; 48 aged 60-70, 21 aged 70-80 and three aged $80-90$ ) who resided in the care facility. All occupied single rooms, except three married couples who shared a room. The residents studied had all lived there for more than five years. Convenience sampling was used and 19 white, mainly Afrikaans-speaking, older people (10 women and nine men) between the ages of 65 and 89 participated in the research. Residents who could express themselves coherently were identified by the staff and invited to take part.

\section{Data collection methods}

On the day of the research, the researchers and 19 participants were introduced to one another by means of an ice-breaking exercise. The participants were invited to position themselves visually at points on a hypothetical line according to how they perceived the quality of their relationships with others, with zero as very negative and 10 as very positive. One woman placed herself at 5, two women placed themselves at 7 , two at 9 and the remainder of the group at 10. Before the participants engaged in the research, the data gathering procedure was explained to them.

Data were gathered by means of the World Café method (Brown, 2002; Schieffer, Isaacs \& Gyllenpalm, 2004). The World Café method requires participants to form small groups consisting of five to seven people. In this instance, participants were randomly assigned a number from one to three and asked to arrange themselves according to their number. Researchers trained in the World Café method were allocated to each group and facilitated group discussions. One of the participants at each table, identified by the group, was asked to give feedback to the bigger group at the end of the data gathering session, with the support of the researcher and the rest of the group. The smaller groups were seated around a table with a large, A2 sheet of paper, refreshments and multi-coloured writing materials to create a congenial atmosphere (Brown, 2002). This offers an accessible research method of obtaining data from large groups of people by means of discussions based on a specific research question (Schieffer et al., 2004). The unique structure of the World Café method used for the study gave all participants an opportunity to be involved in data gathering, and the manner of their involvement stimulated ideas about effective relationships.

Visual data were obtained from images and symbols the participants drew on the paper and textual data from group discussions, which were audio-taped and transcribed verbatim. Every participant had an opportunity to add their views to the paper. The discussion on a specific question by a specific group typically lasted about 20 minutes, and 
the group then rotated to the next table to meet the host or hostess and to participate in the question at that table (Ritch \& Brennen, 2010). In the present research, taking into account some of the participants' difficulty in moving around, the groups remained seated at their tables whilst the older person and the researcher who acted as facilitators moved to the next table with the same question. This process was repeated until all participants had been given the opportunity to respond to all the questions. For the present research, the sheets of paper were pinned to the wall, and the three group hosts or hostesses communicated what the participants had contributed to the different questions. A group discussion followed, during which some of the participants clarified their input and complemented the information with further examples. This part of the data gathering was regarded as member checking.

Each group was provided with one of the positively framed questions and was asked to give input visually and verbally. The assumption underlying positively framed questions is that effective relationships are possible in every group, institution or organisation and that people have the knowledge, wisdom and creativity to relate optimally to one another (Schieffer et al., 2004). For the present study, it was decided to focus on effective relationships and not to engage in problems or challenges. In formulating the questions, it was decided to follow Kitching et al. (2012), who had conducted research into effective interactions between different groups in a school community. Kitching (2010) had obtained rich data when asking participants to describe when they felt engaged and excited in their interactions with others. It was decided to include a similar question in this study as part of the data gathering as the first question. The second question, which focused on a visual representation of interactions, was motivated by the use of visual data as an external narrative to facilitate discussions (Roos, 2008). The last question was motivated by Gilbert's (2006) assumption that people construct the future on the basis of their current experiences.

The following three questions were discussed in the three separate groups.

Group 1: Think about your relationships in this residential facility. What are the meaningful moments when you felt really excited and involved with people?

Group 2: How can you illustrate positive relationships in this residential facility visually by means of a metaphor, a slogan or an image?

Group 3: If your grandchildren were residents of this residential facility, what type of relationships would you like them to form here?

\section{Data analysis}

The symbols and visual images that participants drew on paper to illustrate their perceptions of effective relationships were subjected to visual data analysis. Firstly, the symbols were analysed in terms of the literal meaning of the object. Secondly, they were analysed in conjunction with the textual data obtained from the discussions and thirdly, they were analysed in relation to the research question.
Textual data were gathered by assembling the responses of all the participants during group discussions as well as their written responses. Two levels of analysis were applied to obtain the findings: initially all data (visual and textual) were subjected to inductive thematic analysis (Braun \& Clarke, 2013) and triangulated with the specific question asked. Following this, the themes that were obtained were subjected to direct context analysis using SIGT as the theoretical framework (Hsui-Fang \& Shannon, 2005). The interindividual and group level analysis proposed by SIGT was used to describe the definition of the relationship, relational qualities and needs (inter-individual level) and group norms and dynamics (group level) (Roos, in press; Vorster et al., 2013). As anticipated, the positively framed questions elicited positive emotions and perceptions, which served to provide insight into the inter-individual and group level. This in turn provided insight into effective relationships.

\section{Strategies employed to ensure data quality}

Tracy (2010) identifies the following criteria for good qualitative research, which may be applied to ensure data quality. The topic under investigation is relevant and worthy of studying in light of the growing number of older people and the tendency that more may move into institutionalised residential settings. It is also useful for managers in other organisational settings to gain an understanding of effective relationships. Rich rigour was demonstrated by using theoretical constructs in relational psychology. Researchers were engaged for a prolonged period of time in residential care facilities to study behaviour in these settings (Ellingson, 2009). Furthermore a comprehensive contextualisation of the research context was provided as well as how the data were gathered and analysed. Throughout the process the researchers reflected on their assumptions by having regular discussions of the findings and by being aware of the limitations in the research. Direct quotes from participants' responses were included to provide thick descriptions. Crystallisation of data was obtained through different data analyses. The study adhered to a virtue-ethical approach and complied with procedural, relational and context-specific ethics. Data gathering methods were used to answer the research question that motivated this research.

\section{Ethical considerations}

Before data gathering, ethical approval was obtained from North-West University's (South Africa) ethical committee (NWU-00053-10-S1), the board overseeing the management of various residential care facilities, including the one studied, and the manager of the particular residential care facility. Nineteen participants were informed, on the day of data gathering, about the nature of the research, which was to explore their relational experience in the residential care facility. It was also explained that their participation would be voluntary and that they could withdraw at any time if they so wished. They were assured that data would be treated confidentially and that their identities would not be disclosed. Those who agreed to participate signed informed consent forms. The residents who did not participate were 
either frail, immobile and confined to their beds or rooms, or challenged by cognitive impairments which made it difficult to engage in a coherent discussion. Some residents preferred not to participate and some had other obligations.

\section{Reporting}

Findings will be reported on the three levels of analysis suggested by SIGT and include direct quotes from the participants. The discussion will include verification from literature.

\section{Findings}

Effective relations (caring, warm, satisfying and trusting) in institutionalised settings are important for relational wellbeing and optimal functioning, but research on the topic is scarce. Qualitative research was applied to explore older residents' perceptions of effective relations in a residential setting by asking positively framed questions in applying the World Café method. Visual and textual data were obtained and subjected to different methods of analysis. The findings obtained from the data gathering and analyses are summarised in Table 1 and discussed according to SIGT.

\section{Subjective perceptions}

The positively framed questions naturally elicited positive perceptions. The quotes that are included are used only as examples of the perceptions used to explore what occurs on the inter-individual level and the group level.

\section{In relation to care managers}

The participants perceived the care managers as friendly and trustworthy. One participant remarked: 'We've got the best manageress one could ask for' (Participant 15, female). In relation to carers the participants agreed on 'the friendliness that we receive from them [the manager and staff]; the confidentiality and the care for the residents' (Participant 5, female). 'They are very helpful, patient and they care for us. They love us' (Participant 14, female).

TABLE 1: Themes and subthemes of effective relationship.

\begin{tabular}{ll}
\hline Subthemes & Subjective perceptions \\
\hline In relation to care managers (friendliness and trust) \\
$\begin{array}{ll}\text { Definition of the relationship } & \text { - Leader } \\
\text { Relational qualities of manager (carers) } & \text { - Flexible } \\
\text { in interaction with residents } & \text { - Empathetic } \\
\text { - Congruent } & \text { - Confirmation } \\
\text { Need addressed } & \\
\text { In relation to fellow residents (care) } & \text { - Parallel-defined relationship } \\
\text { Definition of the relationship } & \text { - Giving and receiving empathy } \\
\text { Relational qualities in interaction with } & \text { Unconditional acceptance } \\
\text { fellow residents } & \text { - Effective expression of need for } \\
\text { peeds addressed } & \text { privacy } \\
& \text { - Confirmation } \\
\text { Intra-group level } & \text { - Care as a group norm underpinning } \\
& \text { interactions } \\
\text { Environment in which interactions } & \text { - Supportive group dynamics } \\
\text { took place } & \text { Stimulating environment }\end{array}$ \\
\hline
\end{tabular}

\section{In relation to fellow residents}

The participants experienced care in relation to other residents. A woman resident described the care she received from fellow residents as follows: 'I was in hospital for five weeks and these people carried me. They called me. They were there for me. It was so pleasant to be with them' (Participant 5, female).

\section{Inter-individual level}

The inter-individual level will firstly be discussed in relation to the care managers and then in relation to fellow residents.

\section{In relation to care managers}

In relation to care managers the discussion will focus on the definition of the relationship and relational qualities that were identified by the residents.

Definition of the relationship: The residents appeared to accept care managers taking the lead. One gave an example of this: 'Yes, we know that if we have a problem, they [management] will solve it for you - if you cannot solve it yourself' (Participant 7, male). Although residents accept the leadership position of care managers, they appreciate the person-centred approach in which interactions take place. 'The big thing of management is that they involve people. It is not a top-down approach. They listen to what people want. They are on the ground' (Participant 2, male).

Relational qualities of care managers in relation to residents: Two other residents (participants) who had previously stayed in other residential care facilities compared the two facilities and highlighted the importance of flexibility in managing the care setting:

'I participated in a small group [in the previous care facility], but it had to stop at eight o' clock when they closed everything. It felt like a jail, but not here'. (Participant 17, male)

In addition: 'The people are very morbid there. Here is more freedom. You can come and go as you please' (Participant 8 , female).

The participants experienced the interpersonal style of care managers as congruent: 'What really stands out for me is the care, the authentic care of managers. The people give' (Participant 14, female). Residents expressed that they were confirmed as worthy people. Residents mentioned that care managers recognised their contribution as valuable; they listened to the residents and helped them to deal with their problems. One of the participants said: 'Yes, management listens [confirmation] to the input of ordinary people - their problems and what they struggle with - and they give attention to it' (Participant 2, male).

\section{In relation to fellow residents}

In relation to fellow residents the discussion will focus on the definition of the relationship and relational qualities that were perceived as effective by the residents. 
Definition of the relationship: Relationships amongst fellow residents were defined as parallel or equal. Participants expressed their equal status as follows: 'Here, with us, the youngest 65 and the oldest, 89 . There is no age difference' (Participant 1, male).

Relational qualities of fellow residents: Residents gave and received empathy and reported their appreciation of this kindly interaction. One of the participants compared her present experience of empathy with that in the facility where she had previously resided:

'You know, I was previously at another place. My child died in an accident and they did not even say that they are sorry for me. Here people have sympathy with one another'. (Participant 5, female)

Other participants also mentioned their experience of empathy: 'We listen to one another's problems and we share in one another's hardships' [Participant 13, female]. 'I also like to listen when people speak to me and try to understand what is worrying them and then I also like to pray for people' [Participant 3, female]. She added:

'I think that my strong point is that I can listen. I can observe. I am sensitive to the needs of other people and I can interpret body language'. (Participant 3 , female)

In this case, the differences between people, particularly in terms of religious affiliation, were dealt with by acceptance of one another. According to one participant: 'We respect one another's denominations' (Participant 15, female). Another said: 'Yes, we accept one another, despite [the fact] that we are all different' (Participant 14, female).

In this interpersonal context, residents expressed their need for privacy effectively. This is evident from the following responses: 'If you do not want to talk, then you close your door; but if you want to talk then the people will come to you' (Participant 6, female). Another participant confirmed this: 'If you are unhappy, then you just ask. We do not have to withhold, we can just say [what we want]' (Participant 2, male).

Residents also satisfied their need for confirmation. This was indicated by the way in which they recognised one another's value and importance. One older woman said: 'I always say that I am an outsider, but then they say: no you are not an outsider' (Participant 19, female). Another participant described the efforts residents make to celebrate one another's birthdays: 'For everyone who celebrates their birthday, there is a card that is being signed and placed on their table on their birthday.' Two participants described the importance of birthdays: 'It is an important day for the people who celebrate their birthday and it is their day' (Participant 1, male). And: 'Yes, they feel important, [because] somebody is thinking of them' (Participant 16, male). The participants also praised one another for their efforts to mark the event:

'She deals with everything if there is a birthday. We give the card to her and it is on the person's table who celebrates his or her birthday the next morning, with a chocolate. She deals with everything'. (Participant 1 , male).

\section{Care as a group norm guiding interactions}

The residents' interactions in the residential care setting seemed to be informed by a group norm of care, explained as follows:

'[There is] love for one another, care for one another, listening to one another's problems and sharing in difficult times. Everyone reaches out to one another and is friendly with one another. They make jokes'. (Participant 13, female)

And: 'If someone stays away for a long time, then we begin to ask: where is that person? Why is she gone for such a long time?' (Participant 8, male). The norm guided the helping behaviour described by some of the participants: 'I like to help people, I get pleasure out by helping people, especially in (this residential facility), if you see people battling' (Participant 8, male). And: 'If they cannot do something, help them, show them that you care about them' (Participant 7, male).

\section{Interactions in particular environment}

The environment in which the interactions took place was perceived as stimulating and active: 'We've got a lot of activities here, we are not bored. You can be busy twentyfour hours a day, people can play darts' (Participant 7, male). And: 'Fridays are our rest day, but everyone always invites us to go out somewhere' (Participant 19, female). Many of the participants mentioned the annual Christmas function and were asked why this event was meaningful to them: 'Oh, everyone is very happy and we live here as close friends' (Participant 15, female).

In concluding the research exercise, participants summarised what they regarded as the most important relational qualities for effective relationships: clarity of self-presentation (trust, unreserved trust, trustworthiness, honest communication and open-handedness), unconditional regard (acceptance of one another despite differences and unconditional love), empathy and affirmation (respect), and congruency (sincerity). The outcomes of effective relationships for them were to give and receive physical, emotional and spiritual support (physical support, supportive contact, spiritual support).

\section{Discussion}

The aim of this study was to identify what older residents consider to be effective relationships in a setting caring for older people. Effective relationships contribute to relational well-being and ultimately to mental health. People in an institutional setting spend many hours interacting with one another and the environment. Effective relationships were perceived by older residents in relation to care managers and fellow residents. Positive perceptions (subjective experience) of effective relationships were elicited by asking positively framed questions. The subjective interpretation of the interactions with care managers was that they were friendly and trustworthy and the experience in relation to coresidents were that they were caring. The positive perceptions 
recorded were used to describe what was occurring on an inter-individual and group level. The relationship with care managers was defined as a complementary relationship with care managers in the leading position. On the inter-individual level, residents perceived that care managers were leading in a flexible manner, congruently and empathetically. In this particular setting, the role of the manager is to manage the facility, make decisions and ensure care for older people. Care managers confirmed residents as valued individuals.

The subjective experience of the relationship with fellow residents was being cared for. The relationship between residents was defined as parallel and residents alternated in taking the roles of leaders and followers. The relational qualities that were described in relation to fellow residents were giving and receiving of empathy and unconditional acceptance. Residents perceived that they could express their needs for privacy and they felt confirmed by other residents. Interaction was motivated by their needs for physical, emotional and spiritual support as well as for privacy and affirmation.

The group dynamics that developed spontaneously in this setting were guided by care as a group norm. The interpersonal context in which the interactions between residents and care managers and fellow residents took place was embedded in a stimulating environment. The stimulating environment provided opportunities for close interpersonal contact and various opportunities for engaging with people inside the institution as well as externally.

In linking the findings with literature, the discussion will focus first on residents' relationship with their care managers and then on their relationship with fellow residents. The findings confirmed, similar to what Rockwell (2012) found, that reciprocal caring and warm relationships with care managers and co-residents are important for older people's socio-emotional care. A management style of leading in a flexible, empathetic and congruent manner contributes to an emotionally safe interpersonal context (Vorster et al., 2013). Flexibility enables managers to adopt a meta-reflective position and view the interaction from a second order level (Vorster et al., 2013). Empathy is regarded as a relational quality that facilitates effective interactions between people because they are able to put themselves in the position of the other (Howe, 2013). Managers who lead in a congruent manner co-construct a predictable interpersonal context in which the subjective impact is trust. Trust is identified by Fiske (2000) as one of four core social motives in human interactions. In an interpersonal context in which managers display these relational qualities, and when people are confirmed as worthy, they tend to make their needs known. According to systems theory, establishing patterns of effective interpersonal interactions can create something that is much more than the sum of the individual behaviour in the system (Smith-Acuña, 2011).

In regard to fellow residents, relationships were described as equal. According to Vorster et al. (2013), people in parallel-defined relations can move between positions of following and leading depending on context. This variation in defining relationships also indicates a tendency towards flexibility because the same definition of the relationship, irrespective of the context, is not applied rigidly. Moreover, empathy, unconditional acceptance and confirmation of people are all relational qualities that contribute to effective relationships. In this study, cooperation was observed as a result of successful interpersonal and inter-group contact (Fiske, 2000). Interpersonal interactions in this setting took place in a stimulating environment in which the residents engaged actively with one another. Chiao, Weng and Botticello (2011) found in their study that the involvement of older people in an interactive and socially stimulating environment promotes psychological well-being and reduces symptoms of depression.

The group dynamics in this group provided spontaneous social support (Vinogradov \& Yalom, 1989). In a group such as this, altruism and group cohesion are observed, with group members supporting one another physically and emotionally. Care is the group norm guiding the behaviour of members. These group dynamics and interpersonal interactions can limit depression in residential institutions caring for older people (Hsu, 2012). Despite evidence of group support and cohesion, the subjective experience and individual needs should always be recognised. This is confirmed by one of the male participants (Participant 3, male), who remarked at the end of the inquiry in reference to the ice-breaking exercise at the beginning of the data gathering session: 'Maybe we are not on 10 yet and we have work to do'.

Residents in settings are limited in terms of the availability and variety of relationships. Effective relational qualities can best develop in interpersonal contexts that people perceive as safe. Managers who display effective relational qualities in interpersonal contexts contribute to the development of group dynamics that are underpinned by norms of care. In these groups, individuals are supported and the group provides opportunities for effective interaction.

The World Café method, as a participatory action-based research design, facilitated the identification of the effective relational qualities in a group context. The use of the World Café method can help make participants aware of the quality and potential of relationships in their immediate environment. It is recommended that institutions set out to identify effective relational qualities that can be nurtured to promote effective group dynamics instead of focusing chiefly on problems or challenges. Sensitising managers about the importance of their relationships with residents and showing how they can contribute to the construction of safe interpersonal contexts can help residents to express their needs effectively and will, it is hoped, be able to change a complaint discourse, which often manifests as the ineffective expression of needs (A. De Wet, clinical psychologist, personal communication, May 12, 2012). 


\section{Limitations and recommendations}

The use of positively framed questions may have yielded disproportionately positive results about the potential and quality of relationships in the facility. In addition, the group approach followed in the World Café method did not make provision for incorporating individuals' subjective experiences. The use of a variety of data gathering methods could have accounted for this limitation. The particular setting was chosen expressly on the recommendation of the social worker, who invited residents to participate in the study. It is thus possible that the findings could convey an exaggeratedly positive impression of relationships as a result of the particular group dynamics in this setting. Moreover, the sample used in this study did not include people who were not mobile and could not express themselves coherently. The findings are therefore not generalisable to all the residents and this should be kept in mind in interpreting the results.

\section{Conclusion}

It is suggested that effective relationships and leadership styles in other institutional settings be explored to determine if findings in this study can be confirmed. It is also suggested that qualitative data be used to develop a measurement for effective relationships that can be researched quantitatively.

\section{Acknowledgements Competing interests}

The authors declare that they have no financial or personal relationship(s) that may have inappropriately influenced them when they wrote this article.

\section{Authors' contributions}

V.R. (North-West University) promoted F.D.T. (NorthWest University) for his master's dissertation. The article originated from his research work. V.R. conceptualised the research and gave advice on the research methodology and on interpreting the research results. F.D.T. contributed to the qualitative analysis of the data and interpretation of the findings.

\section{References}

Anthony, L., Suchman, D.J.S., \& Penelope, R.W. (2011). Leading change in healthcare: Transforming organizations using complexity, positive psychology and relationship-centred care. New York, NY: Radcliffe Publishing.

Braun, V., \& Clarke, V. (2013). Successful qualitative research. A practical guide for beginners. London, England: SAGE Publications.

Brown, J. (2002). The World Cafe: A resource guide for hosting conversations that matter. Mill Valley, CA: Whole Systems Associates.

Brownie, S., \& Horstmanshof, L. (2012). Creating the conditions for self-fulfilmen for aged care residents. Nursing Ethics, 19(6), 777-786. http://dx.doi. org/10.1177/0969733011423292

Chiao, C., Weng, L., \& Botticello, A.L. (2011). Social participation reduces depressive symptoms among older adults: An 18-year longitudinal analysis in Taiwan. BMC Public Health, 11(1), 292-300. http://dx.doi.org/10.1186/1471-2458-11-292

Chigeza, S., De Wet, A., Roos., V., \& Vorster, C. (2013). African migrants' experiences of Xenophobic violence in South Africa: A relational approach. Journal of Psychology in Africa, 23(3), 139-143.

Chigeza, S., \& Roos, V. (2011). The resilience of illegal African migrants in South Africa: A relational perspective. Australian Community Psychologist Special Resilience, 23(2), 121-134.
Clissett, P. (2008). Evaluating qualitative research. Journal of Orthopaedic Nursing, 12, 99-105. http://dx.doi.org/10.1016/j.joon.2008.07.009

Creswell, J.W. (2007). Qualitative inquiry \& research design. Choosing among five approaches. (2nd edn.). Thousand Oaks, CA: SAGE Publications, Inc.

Ellingson, L.L. (2009). Engaging crystallization in qualitative research: An introduction. Thousand Oaks, CA: Sage.

Fiske, S.T. (2000). Stereotyping, prejudice, and discrimination at the seam between the centuries: Evolution, culture, mind, and brain. European Journa between the centuries: Evolution, culture, mind, and brain. European Journal of Social Psychology, 30, 299-322. http://dx.doi.
0992(200005/06)30:3\%3C299::AID-EJSP2\%3E3.0.CO;2-F

Fromm, E. (1985). The art of loving. London, England: Thorsons, Harper Collins Publishers.

Gilbert, D. (2006). Stumbling on happiness. New York, NY: Random House, Inc.

Grenade, L., \& Boldy, D. (2008). Social isolation and loneliness among older people: Issues and future challenges in community and residential settings. Australian
Health Review, 32(3), 468-478. http://dx.doi.org/10.1071/AH080468

Hargie, O. (2011). Skilled interpersonal communication. Research, theory and practice. (5th edn.). London, England: Routledge.

Hogan, P.C. (2011). What literature teachers us about emotion. New York, NY Cambridge University Press. http://dx.doi.org/10.1017/CBO9780511976773

Howe, D. (2013). Empathy. What it is and why it matters. Hampshire, England: Palgrave Macmillan.

Hsu, H. (2012). Group-based trajectories of depressive symptoms and the predictors in the older population. International Journal of Geriatric Psychiatry, 27, 854-862. in the older population. International
$\mathrm{http}: / / \mathrm{dx}$.doi.org/10.1002/gps.2796

Hsui-Fang, H. \& Shannon, S.E (2005). Three approaches to qualitative content analysis. Qualitative Health Research, 15(9), 1277-1288. http://dx.doi. org/10.1177/1049732305276687

Hycner, R. \& Jacobs, L. (1995). The healing relationship in Gestalt therapy: A dialogic/ self-psychological approach. Highland, NY: The Gestalt Journal Press.

Kitching, A.E. (2010). Conceptualising a relationship-focused approach to the coconstruction of enabling school communities. Unpublished doctoral dissertation, North-West University, Potchefstroom, South Africa.

Kitching, A.E., Roos, V., \& Ferreira, R. (2012). Towards an understanding of nurturing and restraining relationships in school communities. Journal of Psychology in Africa, 22(2), 187-200.

Lalive d'Epinay, C., Cavalli, S., \& Spini, D. (2003). The death of a loved one: Impact on health and relationships in very old age. Omega. Journal of Death and Dying, 47(3), 265-284. http://dx.doi.org/10.2190/3GMV-PGL9-UD68-NEKW

Lazarus, R.S. (2006). Emotions and interpersonal relationships: toward a personcentred conceptualisation of emotions and coping. Journal of Personality, 74(1) 9-46. http://dx.doi.org/10.1111/j.1467-6494.2005.00368.x

Murphy, K., O'Shea, E., Cooney, A. (2007). Quality of life for older people living in longstay settings in Ireland. Journal of Clinical Nursing, 16(11), 2167-2177. http:// stay settings in Ireland. Journal of Clinical Nursi
dx.doi.org/10.1111/j.1365-2702.2006.01865.x

Neuman, W.L. (2000). Social research methods: Qualitative and quantitative approaches. (4th edn.). Boston, MA: Allan \& Bacon. http://dx.doi.org/10.1557/ PROC-660-JJ8.30.1

Reason, P., \& Bradbury, H. (2006). Introduction: Inquiry and participation in search of a world worthy of human aspiration. In P. Reason, \& H. Bradbury (Eds.), Handbook of Action Research (pp. 1-14). London, England: SAGE Publications.

Ritch, E.L., \& Brennen, C. (2010). Using World Café and drama to explore older people's experience of financial products and services. International Journal of Consumer Studies, 34(4), 405-411. http://dx.doi.org/10.1111/j.1470-6431.2010.00881.x

Rockwell, J. (2012). From person-centred to relational care: Expanding the focus in residential care facilities. Journal of Gerontology Social Work, 55(3), 233-248. http://dx.doi.org/10.1080/01634372.2011.639438

Roos, V. (2008). The Mmogo-method: Discovering symbolic community interactions. Journal of Psychology in Africa, 18(4), 659-668.

Roos, V. (in press). Self-Interactional Group Theory (SIGT) to explain the relational/ interactional nature of intergenerational relations. In V. Roos (Ed.), Selfconstructed visual research towards understanding relational experiences: The Mmogo-method ${ }^{\oplus}$. Dordrecht, The Netherlands: Springer.

Roos, V., \& De Jager, L. (2010). Die subjektiewe ervaring van eensaamheid by ouer dames - Toepassing van die Mmogo-metode ${ }^{\circledR}$ [The subjective experiences of
loneliness among older women - Application of the Mmogo-method ${ }^{\circledR}$ ]. Tydskrif loneliness among older women - Applica
vir Geesteswetenskappe, 50(1), 15-30.

Roos, V., \& Klopper, H. (2010). Older persons' experiences of loneliness: A South African perspective. Journal of Psychology in Africa, 20(2), 281-292.

Roos, V., \& Malan, L. (2012). The role of context and the interpersonal experiences of loneliness among older people in a residential care facility. Global Health Action 5.

Roos, V., \& Nel. C. (2010). The meaning of friendships among older women in a residential care facility. Die Maatskaplike Werk Navorser-Praktisyn/The Socia Work/Practitioner, 22(2), 241-258.

Ryff, C.D., \& Singer, B. (1998). The contours of positive human health. Psychological inquiry, 9(1), 1-28. http://dx.doi.org/10.1207/s15327965pli0901_1

Schieffer, A., Isaacs, D., \& Gyllenpalm, B. (2004). The World Cafe: Part one. World Business Academy, 18(8), 1-16.

Shabangu, T.R., \& Roos, V. (2012). An exploration of the experiences of older persons in an economically deprived residential care facility. Social Work Researcher/ Practitioner, 24(2), 210-228.

Smith-Acuña, S. (2011). System theory in action: Application to individual, couple and family therapy. Hoboken, NJ: John Wiley \& Sons Inc. 
Suchman, A.L. (2006). A new theoretical foundation for relationship-centred care. Journal of General Internal Medicine, 21(1), 40-44. http://dx.doi.org/10.1111/ j.1525-1497.2006.00308.x

Taube, E., Kristensson, J., Midlov, P., Holst, G., \& Jakobsson, UI. (2013). Loneliness among older people: Results from the Swedish national study on aging and
care - Blekinge. The Open Geriatric Medicine Journal, 6, 1-10. http://dx.doi. care - Blekinge. The Open Geriatric
org/10.2174/1874827901306010001

Tracy, S.J. (2010). Qualitative quality: Eight 'big tent' criteria for excellen qualitative research. Qualitative Inquiry, 16(10), 837-851.http://dx.doi. org/10.1177/1077800410383121

Van Biljon, L. \& Roos, V. (2012). The construction of quality of life of older people. Unpublished manuscript, North-West University, Potchefstroom, South Africa.
Victor, C.R., Scambler, S.J., \& Bond, J. (2009). Growing older series: The social world of older people - Understanding loneliness and social Isolation in later life. New York, NY: Open University Press.

Vinogradov, S., \& Yalom, I.D. (1989). Group psychotherapy. Washington, DC: American Psychiatric Press, Inc.

Vorster, C. (2011). Impact: The story of interactional therapy. (1st edn.). Pretoria, South Africa: Satori Publishers.

Vorster, C., Roos, V., \& Beukes, M. (2013). A psycho-diagnostic tool for psychotherapy: Interactional Pattern Analysis. Journal of Psychology in Africa, 23(3), 163-169.

Watzlawick, P., Bavelas, J.B., \& Jackson, D.D. (2011). A study of interactional patterns, pathologies and paradoxes: Pragmatics of human communication. New York, NY: Norton \& Company. 